Adnan H. Bjelak*

Državni univerzitet

u Novom Pazaru
316.722:[37.011.3-51:81'243(497.11 Novi Pazar)

https://doi.org/10.18485/zivjez.2021.41.1.9

Originalni naučni rad

Primljen 02/07/2021

Prihvaćen 26/12/2021

\title{
INTERKULTURNA KOMPETENCIJA NASTAVNIKA JEZIKA NOVOPAZARSKIH ŠKOLA
}

Cilj analize jeste predstavljanje nivoa interkulturne kompetencije nastavnika jezika novopazarskih osnovnih i srednjih škola. U istraživanju sprovedenom u oktobru 2020/21. godine učestvovalo je 35 nastavnika jezika. Istraživanje je sprovedeno anketiranjem nastavnika jezika, gde se anketa sastojala od pitanja zatvorenog i otvorenog tipa, te ispitivala stavove nastavnika jezika o interkulturnoj nastavi, bitnosti sticanja interkulturne kompetencije kroz nastavu jezika, nužnosti interkulturne kompetencije i učenika i nastavnika, razvoju interkulturne osetljivosti, te o percepciji svoje uloge kao medijatora između strane i kulture maternjeg jezika. Kvantitativno-kvalitativnom analizom pristupili smo obradi dobijenih podataka, na osnovu čega smo potvrdili hipotezu da je interkulturna kompetencija neizostavan konstrukt nastave jezika, te podjednako bitna i kod učenika i kod nastavnika.

Ključne reči: kultura maternjeg jezika, kultura stranog jezika, interkulturna osetljivost, interkulturna kompetencija.

\section{Uvod}

Pojam interkulturne kompetencije vrlo je važan u kontekstu vaspitanja i obrazovanja, posebno kad je reč o uspostavljanju interkulturnih odnosa i savremenom obrazovanju koje tendenciozno ide prema prihvatanju i priznavanju različitosti, a ne samo ka otvorenosti prema drugima.

Ajli (2019: 265) smatra da se ,interkulturna kompetencija odnosi na aktivno posedovanje onih karakteristika ličnosti koje doprinose efikasnoj interkulturnoj komunikaciji”, te navodi kako se interkulturna kompetencija „može posmatrati na osnovu tri glavna atributa: znanje, veštine i stavove", upućujući da bi stavovi podrazumevali ,poštovanje, otvorenost i radoznalost”, koji se odnose na ,spremnost za iskorak iz lične zone komfora”; znanje bi podrazumevalo „verovanja, vrednosti

Univerzitet u Novom Pazaru, Vuka Karadžića bb, 36300 Novi Pazar; adnan_bjelak@msn.com 
i norme grupe ljudi koja utiče na komunikacijsko ponašanje pojedinaca", te izdvaja više kategorija znanja: „sociolingvističku svest, kulturnu samosvest, kulturološki specifična znanja i duboko kulturno znanje”; a veštine bi podrazumevale „posmatranje, slušanje, analizu, ocenjivanje, tumačenje". Autor (ibid.: 265) ističe da je od presudnog značaja za razvoj interkulturne kompetencije i kritička samorefleksija.

Dirdorf (2004: 196) interkulturnu kompetenciju analizira kroz niže i više nivoe razvoja (stepenasto), a čiji se ishodi manifestuju unutar i spolja, navodeći da elementi nižih nivoa kompetencije uključuju potrebne stavove (poštovanje, otvorenost i radoznalost), znanje i razumevanje (kulturnu samosvest, duboko razumevanje i sociolingvističku svest) i veštine (slušanje, analiza itd.), ujedno ukazujući da elementi na gornjim nivoima kompetencija uključuju unutrašnje (interne) i vanjske ishode. Autorka (ibid.: 196) smatra da interni ishodi uključuju pomak u nečijem referentnom okviru, dok se spoljni ishodi manifestuju kroz ponašanje i odgovarajući i efikasan način komunikacije u međukulturnim situacijama.

Kompetenciju na sličan način posmatra i Lids Hurvic (2013: 12) smatrajući da se kompetencija odnosi na ,veštine, sposobnosti, znanja ili obuku”, čime se omogućava odgovarajuće ponašanje u određenom kontekstu, bilo da je reč o verbalnom ili neverbalnom delovanju, ističući da ona uključuje „kognitivne, funkcionalne, bihevioralne i etičke elemente”, te da podrazumeva ,sposobnost da se govori i deluje poštujući etička načela, ljudska prava svakog pojedinca ili grupe", što je u skladu i s Beretovim (2013: 153) shvatanjem koji kompetenciju ne posmatra samo kao sposobnost govora, već i kao sposobnost odgovora na zadatu situaciju, poteškoću ili izazov, gde odgovor podrazumeva primenu složenog skupa „vrednosti, stavova, znanja i razumevanja, veština i ponašanja”.

I Benet (2011: 3) interkulturnu kompetenciju shvata kao ,skup kognitivnih, afektivnih i bihevioralnih veština ponašanja”, gde pod kognitivnim veštinama podrazumeva „kulturnu samosvest, znanja o kulturi uopšte, znanje o različitim kulturama i analizu interakcije”. Autor (ibid.: 3) pod afektivnim veštinama podrazumeva „radoznalost, kognitivnu fleksibilnost, motivaciju, otvorenost", a pod bihevioralnim podrazumeva ,slušanje i rešavanje problema, empatiju, veštine prikupljanja informacija”.

Bortini i Behruz (2012: 21) interkulturnu kompetenciju posmatraju kao imperativni kvalitet potreban mladoj osobi za život u savremenom i pluralističkom društvu, smatrajući da ona podrazumeva preuzimanje aktivne uloge u suočavanju sa socijalnom nepravdom i diskriminacijom, da joj je zadatak promovisati i štititi ljudska prava, te da ,zahteva pojačan osećaj solidarnosti u kojoj se individualni strah od drugosti i nesigurnost suzbijaju pomoću kritičkog razmišljanja, empatije i tolerancije", što govori da, složićemo se sa Beretom i njegovim saradnicima (2013: 
9), interkulturna kompetencija jeste kombinacija stavova, znanja, razumevanja i veština koje se primenjuju putem interakcije s drugima, a koja omogućava da: razumemo i poštujemo ljude za koje percipiramo da imaju različite kulturne odrednice od nas; reagujemo na odgovarajući način, efikasno i s poštovanjem pri interakciji i komunikaciji s kulturno drugačijim od nas; uspostavimo pozitivne i konstruktivne odnose s drugačijima; shvatimo sebe kroz susrete s kulturno različitim entitetima, što potvrđuje i Hercigonjino (2017: 110) mišljenje kojim iznosi da biti interkulturno kompetentan znači biti ,svijestan kulture drugih i ne prihvaćati pasivnu društvenu stvarnost već, nasuprot tome, aktivno sudjelovati u njoj, s novim prijedlozima i idejama", što govori i o tome da, smatra autor dalje, interkulturna kompetencija podrazumeva ,individualnost odnosa sa samim sobom, jer stečena kompetencija može biti samo subjektivna i svojstvena određenoj osobi”. Za Bereta (2013: 155), između ostalog, interkulturno kompetentan znači biti spreman za traženje mogućnosti za druženje sa ljudima koji pripadaju različitim kulturama, biti raspoložen za interaktivno komuniciranje s njima, na odgovarajući način i s poštovanjem.

Interkulturno kompetentnu osobu na sličan način posmatra i Leng sa svojim saradnicima (2014: 491-492), ističući kako je jedna od njenih osnovnih osobina sofisticiranost, a ne etnocentričnost, te navodi i pet modela interkulturne kompetencije: „model globalne kompetencije za liderstvo, model globalnog razmišljanja, model multikulturne ličnosti, razvojni model interkulturne osetljivosti i kulturni model inteligencije". Autori (2014: 492-494), analizirajući navedene modele, ukazuju da model globalne kompetencije za liderstvo obuhvata sedamnaest dimenzija organizovanih u tri široka faktora: percepcija, odnos, samoupravljanje; model globalnog razmišljanja oduhvatao bi znanje o kulturi, interkulturnim pitanjima, o ponašanjima koja bi vodila ka interkulturnim delovanjima; model multikulturne ličnosti govori da takve ličnosti treba da budu određene osobinama kao što su: emocionalna stabilnost, socijalna inicijativa, otvorenost, kulturna empatija i fleksibilnost; razvojni model interkulturne osetljivosti opisuje stadijume kroz koje ljudi prolaze kada se suoče s teškoćama u susretu sa drugim kulturama, te podrazumeva stadijume etnocentrizma i etnorelativizma, gde bi stadijum etnocentrizma, objašnjava Gošović sa saradnicima (2007: 7-8), podrazumevao poricanje razlika (u okviru toga separaciju i izolaciju), odbranu koja se manifestuje kroz tri forme (superiornost, omalovažavanje i obrtanje u suprotnost), minimirizanje razlika; stadijum etnorelativizma, navode autori dalje (2007: 8-9), podrazumevao bi prihvatanje razlika (bihevioralni i vrednosni relativizam), adaptaciju na razlike sa svoja dva međustadijuma (empatija i pluralizam), integraciju razlika koja se javlja u dva oblika: kontekstualna evaluacija i konstruktivna marginalnost. Miler i Nugent (2014: 4) smatraju da Benetov model interkulturne osetljivosti predstavlja, 
zapravo, unutrašnju evoluciju i transformaciju od etnocentrizma do etnorelativizma. Na kraju, kulturni model inteligencije, navode Leng i ostali (2014: 494), određen je kao skup onih sposobnosti koje doprinose efikasnijem funkcionisanju u kulturno različitim društvima, te podrazumeva četiri faktora: „metakognitivnu inteligenciju (tj. mentalnu sposobnost za sticanje i razumevanje kulturnog znanja), kognitivnu kulturnu inteligenciju (tj. strukturu znanja o kulturi i kulturnim razlikama), motivacijsku kulturnu inteligenciju (tj. sposobnost usmeravanja energije prema funkcionisanju $u$ interkulturnim situacijama) i kulturnu inteligenciju u ponašanju (tj. fleksibilnost u ponašanju u međukulturnim interakcijama)".

Opservacijom navedenih zapažanja u vezi s interkulturnom kompetencijom zaključujemo da je referentna tačka razvoja interkulturne kompetencije stav, jer „o gotovo svim ljudima koje susrećemo već imamo neke kategorijalne preliminarne informacije, bilo veoma uopštene, bilo nešto preciznije, informacije koje usmeravaju naše misli, osećanja i postupke" (Rot 2000: 270), odnosno informacije na osnovu kojih formiramo stav o nekom kulturološki distinktivnom entitetu. Prihvatajući prethodno, interkulturno kompetentna osoba mogla bi se tretirati i kroz tri svojstva, kako je posmatra i Profile of the Interculturally Effective Person (Kanadski institut za spoljne poslove 2000: 6): „,sposobnost za komunikaciju sa ljudima iz druge kulture na način kojim će steći njihovo poštovanje i poverenje, time i ohrabrujući kooperativnost i produktivnost na radnom mestu koje dovodi do postignuća profesionalnih i radnih ciljeva; sposobnost da prilagodi profesionalne veštine (tehničke i menadžerske) u skladu s lokalnim uslovima i ograničenjima; sposobnost ličnog prilagođavanja i izazivanje osećaja zadovoljstva u kulturi domaćina". S druge strane, Gošović sa saradnicima (2007: 17) smatra da interkulturna osoba nužno mora razviti ,svest o sebi kao o kompleksnom kulturnom biću, svest o uticaju kulture kojoj pripadamo na naše mišljenje i ponašanje, sposobnost da se zajedno sa drugima angažujemo u istraživanju prećutnih pretpostavki koje utiču na naše ponašanje, otvorenost da se testiraju različiti pogledi na svet, načini mišljenja i rešavanja problema”. Interkulturna kompetencija će, u konačnom, doprineti „otvorenosti i sposobnosti za funkcionisanje u uslovima neizvesnosti i susretanjima s drugosti” (Alred 2003: 24-25).

\section{Interkulturna kompetencija nastavnika jezika}

Savremena nastava jezika ${ }^{1}$ zahteva potpuno drugačiji koncept učenja i podučavanja, koji se neće zasnivati isključivo na sticanju samo jezičke kompetencije,

1 Starki (2003: 69) navodi kako je i samo učenje jezika vid interkulturnog iskustva. 
kako je bio slučaj decenijama unazad, već će prepoznavanje kulturne dimenzije biti jedna od ključnih komponenti učenja. Savremena nastava jezika pravi zaokret od pukog sticanja komunikativne kompetencije, koja se odnosi na sposobnost komuniciranja na stranom jeziku, do interkulturne kompetencije koja će predstavljati adekvatno, fleksibilno, etičko delovanje prema kulturi s kojom se dolazi u kontakt, što je u skladu s Jokikokovom (2005: 79) definicijom interkulturne kompetencije, kojom je posmatra kao etičku orijentaciju u kojoj su istaknuti određeni moralno ispravni načini razmišljanja i delovanja.

Posmatrajući je u kontekstu nastave, Bedeković (2011: 144) interkulturnu kompetenciju definiše kao proces tokom kog nastavnik razvija sposobnost prilagođavanja kulturno drugačijim učenicima, modifikujući personalnu percepciju, a u cilju boljeg razumevanja i prilagođavanja uzusima multikulturnosti, te Miler i Nugent (2014: 5-6) upućuju da nastavnik nije taj koji će učenicima prenositi sadržaje kulture, već će im omogućiti da aktivno učestvuju u istraživanju, analiziranju i evaluaciji pronađenih informacija, odnosno, postaviće se kao moderator i neko ko će davati određena pojašnjenja s obzirom na to da, navodi Leng (2011: 14), lična biografija učenika utiče na učenje jezika i percepciju nematernje kulture.

Bajram i Risadžer (1999) dve decenije ranije iznose stav da je uloga nastavnika jezika daleko šira od formiranja komunikativno kompetentnih govornika, te da se oni posmatraju kao posrednici između maternjeg i stranog jezika, odnosno maternje i strane kulture i da u tom slučaju moraju i sami imati dodatna znanja iz kulturne antropologije, veštine i kompetencije potrebne za iznedrivanje interkulturnih govornika² stranih jezika, koji će biti, kako navode Miler i Nugent (2014: 3), optimalno pripremljeni za delovanje u svetu, smatrajući da je to ostvarivo jedino kombinacijom interkulturne kompetencije i jezičkih veština.

Slično Bajramovom i Risadžerovom shvatanju uloge nastavnika u sticanju interkulturnih kompetencija u nastavi jezika, i Ženg i Ženg (2015: 56) smatraju da interkulturna kompetencija ne uključuje samo kompetenciju u lingvističkom i pragmatičnom smislu, nego, što je još važnije, zahteva svest o različitim skupovima kulturnih scenarija i mogućnost posredovanja između različitih kulturoloških identiteta, o čemu govori i Serku (2006: 55), navodeći da se nastava jezika ne može posmatrati isključivo kao lingvistički zadatak, nego je treba posmatrati kao proces sticanja komunikativne kompetencije, gde je inkorporirana i interkulturna dimenzija učenja, što će reći da, ističe autorka (2006: 56-57) dalje, nastavnici moraju prilagoditi svoje stavove o tome šta znači učiti strani jezik i prilagoditi

2 Bajram (2003: 61) upućuje da se sintagma interkulturni govornik može parafrazirati kao interkulturni medijator, napominjući da je upotreba imenice „govornik” znatno korisnija, jer je u vezi s jezikom. 
nastavni sadržaj i svoj pristup nastavi u skladu s tim, ali i podjednako dobro poznavati maternju kulturu i kulturu naroda čiji je maternji jezik onaj koji predaje, te nastavu shvatiti i kao šansu za otklanjanje predrasuda ili animoziteta koje su učenici eventualno stekli pre nego što su se počeli baviti izučavanjem jezika i kulture nekog drugog etnosa. Stoga, nastavu jezika ne treba shvatiti kao praktični aspekat komunikacije, iako su, smatra Onalan (2005: 217, cit. u: Tran, Jung 2018: 2), nastavnici jezika najzainteresovaniji za njega, jer su za druge aspekte, navodi Kramšova (2013: 58-59), vrlo bojažljivi, verujući da aspekte svakodnevne kulture ne poznaju dovoljno dobro. Kramšova (2013: 59) smatra da se nastavnici jezika vrlo često plaše stereotipa i predrasuda koje mogu formirati na osnovu informacija o kulturi koje se nalaze u udžbenicima, te iz tog razloga pribegavaju izučavanju sigurnog - gramatike i vokabulara.

Lidikot (2004: 2) savetuje da nastavnici jezika u interkulturnoj nastavi, moraju obratiti pažnju na: akviziciju o kulturama, poređenje kultura, istraživanje kultura i pronalaženje vlastitog ,trećeg mesta” među kulturama, te smatra da je eksplicitno iznošenje kulturnih sadržaja, za koje misli da nisu nešto što učenici mogu lako „sakupiti”, u nastavi jezika veoma bitno, preporučujući da izučavanje kulturnih sadržaja počne od prvog časa izučavanja jezika. Izučavanje kulture na ovakav način, prema Klipelu (1994: 50), doprineće razvoju tri aspekta: empatije i razumevanja, znanja i komunikativne veštine. Klipel (1994: 50) naglašava da navedena tri aspekta dovode učenike do međukulturne kompetencije.

Fleming (2003: 88) dolazi do ideje da je drama vrlo zahvalna za promovisanje interkulturnosti i sticanje interkulturne kompetencije, te da je vrlo korisna makar u početnim nivoima interkulturnog obrazovanja. Fleming $(2003: 88,99)$ smatra da se davanjem zadataka u kojima će učenici biti u prilici da „obuku ruho druge kulture" prilikom izvođenja predstave, postiže katarza kod učenika i preorijentacija rasističkih stavova, te kako ovakva nastava emocionalno angažuje, gde nije reč o cerebralnoj aktivnosti, već su učenici emocionalno i fizički aktivni, gde postaju otvoreni za novo, a ipak zadržavaju uobičajeno, personalno, a otvorenost i radoznalost recept su za interkulturno iskustvo i formiranje interkulturne osobe (Rajan 2003: 131).

\section{Metodologija istraživanja}

Istraživanje je deo šireg istraživanja u okviru doktorske disertacije pod nazivom Interkulturno obrazovanje i jezička interkulturnost u Republici Srbiji na prostoru Novog Pazara koja se izrađuje na Filološkom fakultetu Univerziteta u 
Beogradu, a koja se bavi ispitivanjem stavova nastavnika jezika i učenika novopazarskih škola o shvatanju pojma kulture, interkulturnosti, interkulturnog obrazovanja, interkulturnoj nastavi, izučavanju elemenata strane i kulture maternjeg jezika na nastavi jezika, aspektima kulture kroz nastavu jezika, kao i ispitivanjem njihove kulturne osvešćenosti. Istraživanje je realizovano u oktobru školske 2020/21. godine, na osnovu ankete koja je sadržala pitanja otvorenog i zatvorenog tipa, u kojoj je učestvovalo 35 nastavnika jezika (14 nastavnika stranih jezika i 21 nastavnik maternjeg jezika) i 83 učenika (43 učenika osmog razreda osnovne škole i 40 učenika četvrtog razreda srednje škole). Istraživanje je izvršeno na području Novog Pazara u sledećim školama: OŠ „Rifat Burdžović Tršo”, OŠ „Vuk Karadžić”, OŠ „Desanka Maksimović”, OŠ „Mur”, Medicinska škola „Dva heroja”, „Gimnazija”. Od 35 nastavnika jezika u novopazarskim školama, koji su obuhvaćeni anketom, 20 radi u osnovnoj školi, a 13 u srednjoj, dok dvoje njih rade i u osnovnoj i u srednjoj školi. Ukupno 88,5\% $(n=31)$ radi u samo jednoj školi, dok četvoro radi u više škola. Kao nastavnici jezika njih $25,7 \%(n=9)$ rade manje od 5 godina, isti procenat $\mathrm{u}$ intervalu od 5 do 10 godina, dok 48,6\% $(\mathrm{n}=17)$ radi više od 10 godina. $65,7 \%(\mathrm{n}=23)$ njih ima položen stručni ispit, dok $34,3 \%(\mathrm{n}=$ 12) stručni ispit još nije položilo. Pored jezika koji predaju (maternji ili strani), oko $40 \%$ njih govori i neki/još neki od stranih jezika: ruski $(n=4)$, nemački $(n=$ $3)$, turski $(n=2)$, francuski $(n=2)$, italijanski $(n=2)$ i albanski $(n=1) \cdot 11,4 \%(n$ 4) njih izjasnilo se da je boravilo u zemlji u kojoj se govori jezik koji predaju: troje je boravilo turistički, dok je jedno boravilo na profesionalnom usavršavanju u trajanju do mesec dana.

Dobijene rezultate obrađujemo kvantitativno-kvalitativnom analizom, čime potvrđujemo našu hipotezu da je interkulturna kompetencija neizostavan konstrukt nastave jezika, te podjednako bitna i kod učenika i kod nastavnika, što predstavljamo u nastavku.

\section{Rezultati istraživanja $i$ analiza}

Ovim delom istraživanja ispitivali smo stavove nastavnika jezika o interkulturnoj nastavi i interkulturnoj kompetenciji, da li smatraju da je njihova nastava dovoljno interkulturna, te u kojoj meri im nastava jezika služi za promovisanje elemenata interkulturnosti i da li smatraju da ovakvo učenje može rezultirati sveobuhvatnom ličnošću učenika (Tabela 1), da li sebe smatraju medijatorom između strane i kulture maternjeg jezika, te o bitnosti personalne interkultune kompetencije (Tabela 2). 
Tabela 1. Stavovi nastavnika jezika o interkulturnosti i interkulturnoj nastavi

\begin{tabular}{|l|c|c|c|c|}
\cline { 2 - 5 } \multicolumn{2}{|c|}{} & \multicolumn{2}{|c|}{$\mathrm{DA}$} & \multicolumn{2}{|c|}{$\mathrm{NE}$} \\
\cline { 2 - 6 } & $\mathrm{n}$ & $\%$ & $\mathrm{n}$ & $\%$ \\
\hline $\begin{array}{l}\text { Da li ste u toku studija i/ili profesionalnog } \\
\text { usavršavanja imali priliku da se obučite za } \\
\text { interkulturnu komunikaciju }\end{array}$ & 11 & 31,4 & 24 & 68,6 \\
\hline $\begin{array}{l}\text { Da li smatrate da je Vaša nastava usmerena ka } \\
\text { tradicionalnoj nastavi }\end{array}$ & 18 & 51,4 & 17 & 48,6 \\
\hline $\begin{array}{l}\text { Da li smatrate da tradicionalna nastava doprinosi } \\
\text { razvoju interkulturnosti više nego savremena }\end{array}$ & 10 & 28,6 & 25 & 71,4 \\
\hline $\begin{array}{l}\text { Da li smatrate da je Vaša nastava usmerena ka } \\
\text { interkulturnoj nastavi }\end{array}$ & 26 & 74,3 & 9 & 25,7 \\
\hline $\begin{array}{l}\text { Da li smatrate da je Vaša nastava dovoljno } \\
\text { interkulturna }\end{array}$ & 29 & 82,9 & 6 & 17,1 \\
\hline $\begin{array}{l}\text { Da li smatrate da je kroz nastavu jezika sticanje } \\
\text { interkulturne kompetencije jednako važno kao i } \\
\text { sticanje jezičkih veština }\end{array}$ & 30 & 85,7 & 5 & 14,3 \\
\hline $\begin{array}{l}\text { Da li kroz nastavu jezika utičete na razvijanje } \\
\text { interkulturne osetljivosti kod učenika }\end{array}$ & 27 & 77,1 & 8 & 22,9 \\
\hline $\begin{array}{l}\text { Da li kroz nastavu jezika kod učenika razvijate } \\
\text { toleranciju prema pripadnicima drugih kultura }\end{array}$ & 35 & 100 & - & - \\
\hline $\begin{array}{l}\text { Da li smatrate da različiti kulturni sadržaji na nastavi } \\
\text { jezika mogu doprineti uklanjanju predrasuda o } \\
\text { drugim kulturnim grupama }\end{array}$ & 33 & 94,3 & 2 & 5,7 \\
\hline $\begin{array}{l}\text { Da li nastavni sadržaji dovoljno promovišu moralno } \\
\text { i odgovorno ponašanje učenika u interakciji sa } \\
\text { pripadnicima druge kulture }\end{array}$ & 24 & 68,6 & 11 & 31,4 \\
\hline $\begin{array}{l}\text { Da li nastavni sadržaji pomažu učenicima u } \\
\text { formiranju osećaja brige za druge (one bliske, ali i } \\
\text { udaljene) }\end{array}$ & 27 & 77,1 & 8 & 22,9 \\
\hline $\begin{array}{l}\text { Da li kroz nastavu jezika poredite elemente strane } \\
\text { kulture sa kulturom maternjeg jezika }\end{array}$ & 33 & 94,3 & 2 & 5,7 \\
\hline $\begin{array}{l}\text { Da li smatrate da upoređivanje sličnosti i razlika } \\
\text { leksike stranog i maternjeg jezika može doprineti } \\
\text { razvoju interkulturnosti }\end{array}$ & 31 & 88,6 & 4 & 11,4 \\
\hline
\end{tabular}


Tabela 2. Stavovi nastavnika jezika o njihovoj ulozi medijatora između strane i kulture maternjeg jezika i bitnosti personalne interkultune kompetencije

\begin{tabular}{|l|c|c|c|c|}
\cline { 2 - 5 } \multicolumn{1}{c|}{} & \multicolumn{2}{|c|}{ DA } & \multicolumn{3}{c|}{ NE } \\
\cline { 2 - 5 } \multicolumn{1}{c|}{} & $\mathrm{n}$ & $\%$ & $\mathrm{n}$ & $\%$ \\
\hline $\begin{array}{l}\text { Da li sebe smatrate medijatorom između strane i } \\
\text { kulture maternjeg jezika }\end{array}$ & 31 & 88,6 & 4 & 11,4 \\
\hline $\begin{array}{l}\text { Da li smatrate da je interkulturna kompetencija } \\
\text { podjednako važna i za nastavnike, kako i za učenike }\end{array}$ & 33 & 94,3 & 2 & 5,7 \\
\hline
\end{tabular}

Dobijeni podaci govore nam da dve trećine nastavnika jezika, što je $68,6 \%$ njih, koji rade u osnovnim i/ili srednjim školama u Novom Pazaru nije imalo priliku da se u toku studija ili profesionalnog usavršavanja obuči za interkulturnu komunikaciju, dok je samo njih 31,4\% tu priliku imalo, što je možda i posledica toga da već malo više od pola njih, odnosno $51,4 \%$, smatra da je njihova nastava usmerena ka tradicionalnoj nastavi, čiji stavovi sa $71,4 \%$ govore da tradicionalna nastava ne doprinosi interkulturnosti u toj meri u kojoj to čini savremena nastava, dok je 48,6\% mišljenja da njihova nastava nije protradicionalno orijentisana. S druge strane, većina nastavnika jezika mišljenja je da je njihova nastava ipak dovoljno interkulturna $(82,9 \%)$. Ovakav stav opravdan je time što su jedinstvenog mišljenja da na nastavi jezika kod učenika razvijaju toleranciju prema pripadnicima drugih kultura (100\%), gde u 94,3\% slučajeva elemente strane kulture porede sa kulturom maternjeg jezika, ali i $88,6 \%$ njih smatra i da upoređivanje sličnosti i razlika leksike stranog i maternjeg jezika može doprineti razvoju interkulturnosti. Njihovo shvatanje, u 77,1\% slučajeva, ide ka tome da oni na taj način utiču i na razvijanje interkulturne osetljivosti kod učenika, te u $85,7 \%$ slučajeva smatraju da je sticanje interkulturne kompetencije podjednako važno kao i sticanje jezičkih veština, ali i 94,3\% nastavnika jezika smatra da je interkulturna kompetencija podjednako važna i za njih, kako i za učenike.

Nastavnici jezika stava su da različiti kulturni sadržaji mogu doprineti uklanjanju predrasuda o drugim kulturnim grupama (94,3\%), da promovišu moralno i odgovorno ponašanje učenika u interakciji sa pripadnicima druge kulture $(68,6 \%)$, ali pomažu učenicima i u formiranju osećaja brige za druge, one bliske, ali i udaljene $(77,1 \%)$. S tim u vezi, $88,6 \%$ nastavika jezika sebe smatra medijatorom između strane i kulture maternjeg jezika, kakav rezultat ukazuje na činjenicu da nastavnici jezika prepoznaju bitnost interkulturnih elemenata u obrazovanju, te da su dovoljno svesni svoje uloge u podsticanju kulturne osvešćenosti kod učenika. 


\section{Zaključna razmatranja}

$\mathrm{Na}$ osnovu rezultata dobijenih istraživanjem, saznajemo da:

osim jedne trećine nastavnika jezika, ostali nisu imali priliku da se obuče za interkulturnu komunikaciju, ali uvek u velikom procentu smatraju da je na nastavi jezika sticanje interkulturne kompetencije jednako važno kao i sticanje jezičkih veština, kod učenika razvijaju toleranciju prema pripadnicima drugih kultura, različitim kulturnim sadržajima na nastavi jezika doprinose uklanjanju predrasuda o drugim kulturnim grupama, pomoću nastavnih sadržaja dovoljno promovišu moralno i odgovorno ponašanje učenika u interakciji sa pripadnicima druge kulture, nastavni sadržaji pomažu učenicima u formiranju osećaja brige za druge (one bliske, ali i udaljene), kroz nastavu jezika komparativno izučavaju elemente strane i kulture maternjeg jezika, te smatraju da upoređivanjem sličnosti i razlika leksike stranog i maternjeg jezika mogu doprineti razvoju interkulturnosti;

skoro polovina nastavnika jezika, obuhvaćenih istraživanjem, smatra da je njihova nastava usmerena i ka tradicionalnoj nastavi, upućujući da tradicionalna nastava ne može doprineti razvoju interkulturnosti u onoj meri u kojoj to čini savremena nastava, na osnovu čega zaključujemo da nastava jezika u novopazarskim školama još nije usklađena sa savremenim stavovima o interkultunoj nastavi. Međutim, iako nas rezultati istraživanja dovode do ovakvog zaključka, što je i očigledna istina, nastavnici jezika smatraju da nastava jezika ipak nudi povoljne uslove za sticanje interkulturne kompetencije, koja je važna koliko i ovladavanje gramatičkim formama i leksikom određenog jezika.

nastavnici jezika dovoljno su svesni svoje uloge u podsticanju razvoja interkulturne osvešćenosti kod učenika, te sebe smatraju medijatorom između kulture maternjeg jezika i strane kulture, a nastavu jezika, i pored toga što su vrlo podeljeni u mišljenju da učenici kroz dosadašnje obrazovanje nisu stekli bazu za interkulturni dijalog, ključnim faktorom za razvoj interkulturne orijentacije mladih;

nastavnici jezika, u konačnom, prepoznaju bitnost usmerevanja koncepta obrazovanja u Republici Srbiji ka proevropskim vrednostima, prilagođavanju izazovima globalizacije i težnji ka evropskim integracijama.

Uzimajući u obzir saznanja do kojih smo došli na osnovu našeg istraživanja sprovedenog u novopazarskim osnovnim i srednjim školama, a imajući u vidu cilj unapređenje interkulturnog obrazovanja i interkulturne kompetencije, podjednako važne i za učenike i nastavnike jezika, zaključujemo da je neophodno obratiti pažnju na sledeće aspekte i delovati na sledećim poljima:

reforma postojećih kurikuluma, koji se neće posmatrati kao „paket znanja” 
koji ćemo zatvoriti nakon određenog ciklusa obrazovanja, nego koji će doprineti razvoju interkulturno kompetentne ličnosti, što govori o tome da bi nastavni kurikulumi trebalo da budu usmereni ka integraciji različitih sadržaja (i kulture maternjeg jezika, i kulture jezika koji su označeni kao nematernji ili kao strani), s posebnom napomenom da, prilikom konceptuiranja kurikuluma trebalo bi imati više u vidu sadržaje koji se inkorporiraju, jer će se učenici kroz sadržaje koji ostavljaju prostor za polemiku, znatno bolje upoznati sa kulturom kojoj ne pripadaju u odnosu na izučavanje sadržaja koji im nude mogućnost pukog ovladavanja činjenicama o nematičnim kulturama;

korisno bi bilo organizovati seminare za interkulturnu edukaciju nastavnika i jezičkih i nejezičkih predmeta, s ciljem formiranja nastavnika osposobljenih za sprovođenje interkulturne nastave.

\section{LITERATURA}

Ajli 2019: O. A. Ilie, The intercultural competence. Developing effective intercultural communication skills. International Conference Knowledge-based organization, $\mathrm{XXV}(2)$.

Alred 2003: G. Alred, Becoming a 'Better Stranger': A Therapeutic Perspective on Intercultural Experience and/as Education. In G. Alred, M. Byram and M. Fleming (eds.), Intercultural Experience and Education, G. Britain: Cromwell press, 14-31.

Bajram 2003: M. Byram, On Being 'Bicultural' and 'Intercultural', In G. Alred, M. Byram, M. Fleming (eds.), Intercultural Experience and Education, G. Britain: Cromwell press, 50-67.

Bajram, Risadžer 1999: M. S. Byram, K. Risager, Language teachers, politics and cultures. Multilingual Matters Ltd.

Bedeković 2011: V. Bedeković, Interkulturalna kompetencija cjeloživotnog obrazovanja nastavnika. Pedagogijska istraživanja, 8(1), 139-151.

Benet 2011: J. M. Bennett, Proceedings from 2011 AIEA Conference Workshop: Developing Intercultural Competence for International Education Faculty and Staff. San Francisco, CA: AIEA.

Beret 2013: M. Barrett, Intercultural competence: a distinctive hallmark of interculturalism, In M. Barett (edd.), Interculturalism and multiculturalism: similarities and differences, Council of Europe Publishing, 147-169.

Beret, Bajram, Ildiko, Mompoan Gelard, Filipu 2013: M. Barrett, M. Byram, L. Ildikò, P. Mompoint Gaillard, S. Philippou, Developing Intercultural Com- 
petence through Education [Online], [https://www.academia.edu/3150166/ Developing_intercultural_competence through_education].

Bortini, Behruz 2012: P. Bortini, M. A. Behrooz, Intercultural Competence [Online], [https://www.salto-youth.net/downloads/4172740/Intercultural\%20 Competence\%20Research\%20Report\%20-\%20final.pdf].

Dirdorf 2004: D. K. Deardorff, The identication and assessment of intercultural competence as a student of international education at institutions of higher education in the United States (dissertation), University of North Carolina, Raleigh, NC, USA [Online], [https://pdfs.semanticscholar.org/db2e/56ea5ad10c5d5276b198c3cd00764f0d5aee.pdf? $\mathrm{ga}=2.153352188 .517580015 .1584836059-723047074.1584836059]$.

Fleming 2003: M. Fleming, Intercultural Experience and Drama, In G. Alred, M. Byram, M. Fleming (eds.), Intercultural Experience and Education, G. Britain: Cromwell press, 87-101.

Gošović sa saradnicima 2007: R. Gošović, S. Mrše, M. Jerotijević, D. Petrović,

V. Tomić, Vodič za unapređenje interkulturalnog obrazovanja. Beograd:

Fond za otvoreno društvo, Grupa MOST.

Hercigonja 2017: Z. Hercigonja, Interkulturalni odgoj i obrazovanje kao imperativ razvoja interkulturalnih kompetencija. Socijalne teme 2017, 103-115.

Jokikoko 2005: J. Jokikokko, Interculturally trained Finnish teachers' conceptions of diversity and intercultural competence. Intercultural Education, 16, 69-93.

Kanadski institut za spoljne poslove 2000: Canadian Foreign Service Institute, Centre for Intercultural Learning, A profile of the interculturally effective person. Department of Foreign Affairs and International Trade, Canada.

Klipel 1994: F. Klippel, Cultural Aspects in Foreign Language Teaching. In J. Kramer, B. Lenz, G. Stratman (eds.), Journal for the Study of British Cultures, Vol. 1. No 1/94, Germany: Müller + Bass, 49-63.

Kramš 2013: C. Kramsch, Culture in foreign language teaching. Iranian Journal of Language Teaching Research, 1(1), 57-78.

Leng 2011: K. Lange, Perspectives on Intercultural Competence. A Textbook Analysis and an Empirical Study of Teachers ' and Students 'Attitudes [Online], [https://refubium.fuberlin.de/bitstream/handle/fub188/14008/Perspectives on Intercultural Competence.pdf?sequence $=1$ ]

Leng, Eng, Ten 2014: K. Leung, S. Ang, M. L. Tan, Intercultural Competence. Annual Review of Organizational Psychology and Organizational Behaviour, 1, 489-519. 
Lidikot 2004: A. J. Liddicoat, Intercultural language teaching: Principles for practice. New Zealand Language Teacher 30.

Miler, Nugent 2014: A. K. Moeller, K. Nugent, Building intercultural competence in the language classroom [Online]. Faculty Publications: Department of Teaching, Learning and Teacher Education, [https://digitalcommons.unl. edu/cgi/viewcontent.cgi?article $=1160 \&$ context=teachlearnfacpub] $]$.

Rajan 2003: M. P. Ryan, Searching for the Intercultural Person. In G. Alred, M. Byram, M. Fleming (eds.), Intercultural Experience and Education, G. Britain: Cromwell press, 131-155.

Rot 2000: K. Rot, Slike u glavama. Beograd: Biblioteka XX vek.

Serku 2006: L. Sercu, The foreign language and intercultural competence teacher: the acquisition of a new professional identity. Intercultural Education, 17(1), 55-72.

Starki 2003: H. Starkey, Intercultural competence and education for democratic citizenship: implications for language teaching methodology. In M. Byram (ed.), Intercultural competence, Strasbourg: Council of Europe, 63-84.

Tran, Jung 2018: T. Q. Tran, T. M. Doung, The effectiveness of the intercultural language communicative teaching model for EFL learners. Asian-Pacific Journal of Second and Foreign Language Education 3.

Ženg, Ženg 2015: X. Zhang, J. Zhang, English Language Teaching and Intercultural Communication Competence. International Journal for Innovation Education and Research, 3(8), 55-59. 


\title{
Adnan Bjelak
}

\section{INTERCULTURAL COMPETENCE OF LANGUAGE TEACHERS IN NOVI PAZAR SCHOOLS}

\begin{abstract}
Summary
The aim of the analysis is to present the level of intercultural competence of language teachers in Novi Pazar primary and secondary schools. In a survey conducted in October 2020/21. 35 language teachers participated in the year. The research was conducted by surveying language teachers, where the survey consisted of closed and open questions, and examined the attitudes of language teachers about intercultural teaching, the importance of acquiring intercultural competence through language teaching, the need for intercultural competence and students and teachers, the development of intercultural sensitivity and perception their role as mediators between the party and the mother tongue culture. We approached the presentation of the obtained data with quantitative-qualitative analysis, on the basis of which we confirmed the hypothesis that intercultural competence is an indispensable construct of language teaching, and equally important for students and teachers.
\end{abstract}

Keywords: mother tongue culture, foreign language culture, intercultural sensitivity, intercultural competence. 